\title{
Descarga líquida e sólida em suspensão no Rio Guaíba, RS, Brasil
}

\author{
Fernando Comerlato SCOTTÁ ${ }^{1,2}$, Mauro Michelena ANDRADE ${ }^{3}$, Jair WESCHENFELDER ${ }^{1}$, \\ Elírio Ernestino TOLDO JR. ${ }^{1} \&$ José Carlos Rodrigues NUNES'
}

1 Programa de Pós-graduação em Geociências, Universidade Federal do Rio Grande do Sul. Av. Bento Gonçalves, 9.500, CEP 91.540-000, Porto Alegre, RS, Brasil (fernandoscotta.sema@gmail.com, jair.weschenfelder@ufrgs.br, toldo@ufrgs.br, jose.nunes@ufrgs.br).

2 Departamento de Recursos Hídricos e Saneamento, Secretaria do Estado do Meio Ambiente e Infraestrutura do Rio Grande do Sul. Av. Borges de Medeiros, 1501 - $7^{\circ}$ andar - Centro Histórico, Porto Alegre - RS, 90119-900, Porto Alegre, RS, Brasil (fernando-scotta@sema.rs.gov.br).

3 Programa de Pós-Graduação em Ciência e Tecnologia Ambiental, Escola do Mar Ciência e Tecnologia. Universidade do Vale do Itajaí. Rua Uruguai, 458, Bloco D 8, Sala 102, Caixa Postal 360, CEP 88.302-202, Itajaí, SC, Brasil (michelena@univali.br).

Resumo. O objetivo deste trabalho é calcular a descarga líquida (Qliq) e descarga sólida (Qss) no Rio Guaíba utilizando um sensor perfilador acústico de correntes por Doppler (PACD) comparar a Qliq medidas com a vazão dos rios tributários, oscilações de nível da água, direção e intensidade dos ventos. Foi criada uma equação de calibração do PACD para estimar a concentração de sedimentos em suspensão (CSS) e Qss comparando dados do método gravimétrico in situ e de retroespalhamento acústico do PACD. Uma relação exponencial se adaptou melhor no conjunto de dados, com $\mathrm{R}^{2}$ de 0,7 . Foi possível realizar um estudo abrangente sobre as variáveis Qliq e Qss no Guaíba. Os dados de Qliq medidos possuem valores próximos à soma dos dados de vazão dos rios Jacuí, Taquarí, Caí e Sinos. Não foi possível ajustar uma curva-chave entre vazão e a régua localizada no Cais Mauá devido as oscilações do vento que alteram o nível da água na desembocadura deste sistema fluvial, inclusive com situações de inversão do fluxo registradas nos perfis de corrente que foram relacionadas com a ocorrência de ventos nos quadrantes S e SE. Para a variável Qss, os valores apresentaram grande variabilidade, com mínimos e máximos de 776 a 118.130 t/dia. A possibilidade da calibração do sensor PACD para estimar o CSS no Guaíba serve como base para estimar a quantidade de volume de sedimentos que ingressam no Guaíba.

Palavras-chave. sedimentos em suspensão, hidrodinâmica, perfiladores acústicos.

\begin{abstract}
LIQUID AND SUSPENDED SOLID DISCHARGE IN GUAíBA RIVER, RS, BRAZIL. This paper aims at calculate Qliq and Qss in Guaíba using a PACD sensor $(1.5 \mathrm{MHz})$. It is also the objective of this work to compare the Qliq measures with the flow of the tributary rivers, with oscillations of water level, direction and intensity of the winds in this environment. A PACD calibration equation was created to estimate CSS and Qss by comparing data from the in situ gravimetric method and acoustic backscatter data from the PACD. An exponential relation was the best fit in the data set, with $\mathrm{R}^{2}$ of 0.7 . It was possible to carry out a comprehensive study on Qliq and Qss variables in Guaíba. The measured Qliq data have values close to the sum of the flow data of the Jacuí, Taquarí, Caí and Sinos rivers. It was not possible to adjust a key curve between flow and the ruler located in Cais Mauá due to the wind oscillations that alter the water level. The wind action caused the flow inversion of this system. Two inversion situations were recorded in the current profiles at the Guaíba entrance and were related to the occurrence of winds in the $S$ and SE quadrants. For the Qss variable, the values presented great variability, with minimum and maximum values of 776 to 118,130 t/day. The possibility of PACD sensor calibration to estimate CSS in the Guaiba serves as a basis for estimating the amount of sediment volume that is transported to the Guaiba watershed.
\end{abstract}

Keywords. suspended sediment, hydrodynamic, acoustic profilers 


\section{Introdução}

O planejamento e gestão dos recursos hídricos dependem de uma eficiente avaliação dos fluxos superficiais e subterrâneos, incluindo confiabilidade na predição de vazões (Salla et al., 2015). Avaliações contínuas, precisas e automáticas da descarga líquida dos rios sob várias condições de fluxo, incluindo condições de seca e inundação, são de vital importância (Nihei \& Kimizu, 2008). Apesar disso, diversas são as limitações para uma rede de dados robusta dessa variável, como: falta de recursos para manutenção e atualização de banco de dados, consistência de formatos de dados, documentação limitada, falta de metadados e políticas restrita de acesso (Do et al., 2018).

Questões relativas à gestão e controle de sedimentos em suspensão frequentemente recebem ainda menos atenção nas políticas e em programas de gerenciamento de água (Liu et al., 2017). Uma das razões é a dificuldade de obtenção de dados in situ de sedimentos em suspensão, raramente produzindo séries temporais por longos períodos (Oeurng et al., 2010). No Brasil, a rede de monitoramento de estações sedimentométricas mostra esse panorama. Enquanto que a rede fluviométrica com medições de descarga líquida apresentava 1.763 estações no ano de 2007, a rede sedimentométrica tinha apenas 535 estações (ANA, 2017).

O sedimento em suspensão nas águas continentais interiores tem influência nos processos ecológicos dos sistemas aquáticos (Donohue \& Molinos, 2009). Sua distribuição pode ser um indicador de qualidade ambiental, problemas de poluição e saúde pública (Heininger et al., 2007; Heise \& Föstner, 2007; Oeurng et al., 2010). Além disso, muitos rios ao redor do mundo estão enfrentando problemas como o declínio da carga de sedimentos, principalmente devido à construção de barragens e outras estruturas de controle, causando retenção de sedimentos em reservatórios e declínio a jusante (Liu et al., 2017).

O Rio Guaíba recebe o deságue de nove sub-bacias as quais se estendem pelo centro e nordeste do Estado do Rio Grande do Sul (RS) e formam a Região Hidrográfıca do Guaiba (RHG), em uma área de aproximadamente $84.763 \mathrm{~km}^{2}$, que abrange mais de 250 municípios (Nicolodi et al., 2010) e aproximadamente 30\% da área do RS (Fig. 1). A área superficial do Rio Guaíba é de 496 km² e extensão aproximada de 50 km, entre a Ponta do Gasômetro e a Laguna dos Patos (Fig. 1). Possui profundidade média de 2 m (Nicolodi, 2007), com a presença de um canal com maiores profundidades, variando entre 4 a $8 \mathrm{~m}$ (DNAEE, 1983). O clima da área de estudo é do tipo Cfa (subtropical úmido com verão quente) segundo a classificação de Koppen (Alvares et al., 2013). A precipitação pluvial anual é na ordem de 1400 mm/ano (Viana et al., 2006; CPRM, 2020) e os regimes de ventos são predominantes do quadrante leste (Livi, 1998; Camargo, 2002; Nicolodi, 2007).

A rede de drenagem formadora da $\mathrm{RHG}$ cruza por diferentes litologias, reunidas em três grandes províncias geológicas (Porcher \& Lopes, 2000): 1) Província Mantiqueira constituída pelas litologias do Escudo Sul-Rio-Grandense (ESRG), 2) Província Paraná, composta pela sucessão sedimentar e pelos derrames básicos a ácidos da Formação Serra Geral na Bacia do Paraná (BP) e; 3) Província Costeira (PC), formada pelos sedimentos cenozoicos da planície costeira. A contribuição sedimentar destas províncias para a $\mathrm{RHG}$ é repartida do seguinte modo, 35\% pelo ESRG, 55\% pela BP (destes, 35\% são das unidades vulcânicas e 20\% das sedimentares) e 10\% da PC (Delaney, 1965). O Guaíba, localizado numa área limítrofe dessas províncias, corresponde ao final da rede de drenagem da RHG, onde, portanto, concentram-se sedimentos de origem plutônica, vulcânica e sedimentar, oriundos principalmente dos rios Jacuí, Taquari, Caí e Sinos (Toldo Jr., 1994).

O sedimento de fundo do Guaíba caracteriza-se por apresentar tamanho areia nas áreas mais rasas, até a isóbata de $3 \mathrm{~m}$, e fino nas áreas mais profundas, no canal e adjacências (Bachi et al., 2000; Laybauer \& Bidone, 2001; Scottá et al., 2019). A ressuspensão do sedimento fino nas áreas mais rasas ocorre devido à geração de ondas produzidas pela ação dos ventos (Nicolodi et al., 2007; Nicolodi et al., 2013), sendo este, portanto, uma importante forçante deste sistema. 


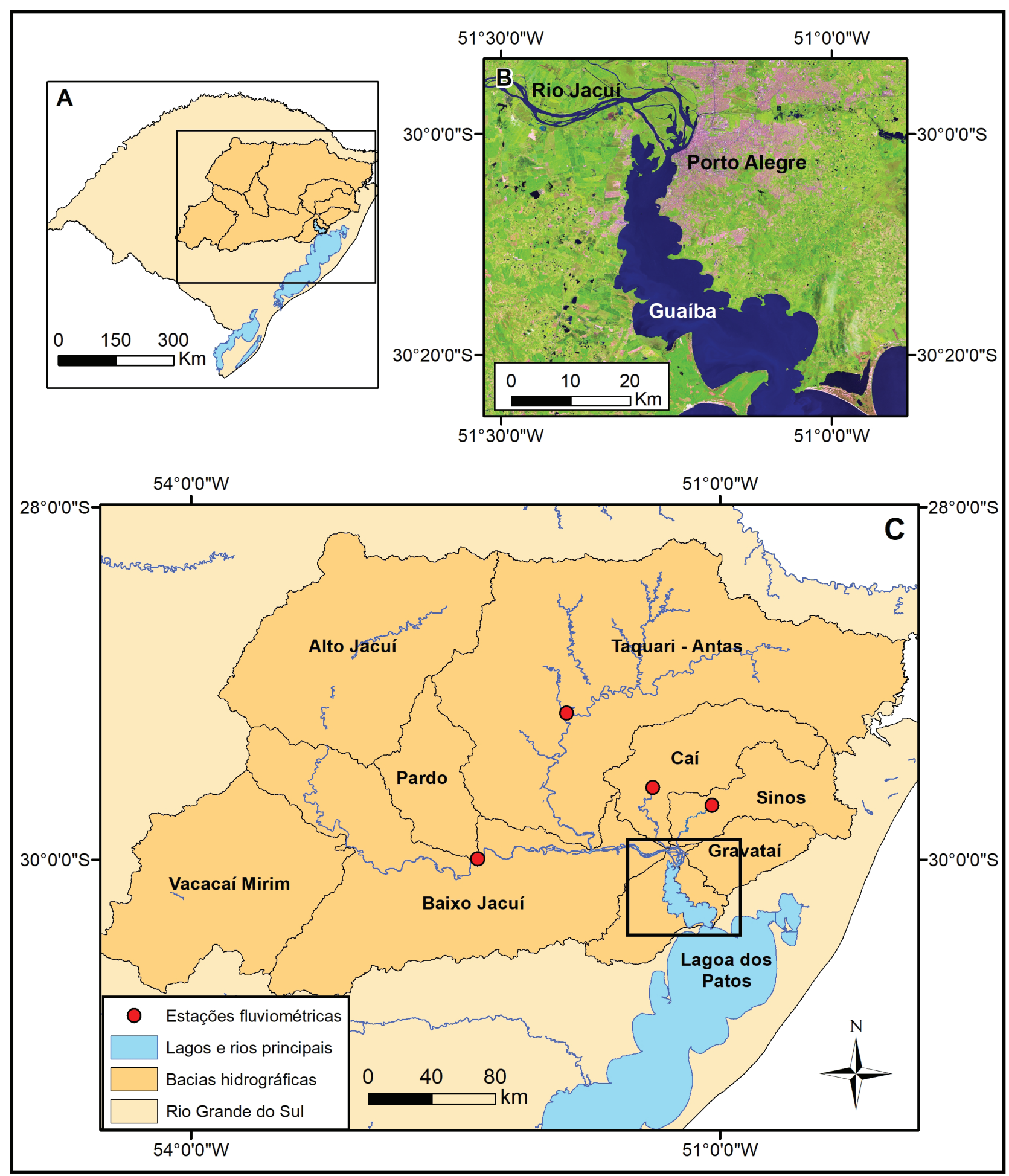

Figura 1. Área de estudo. A) Localização da Região Hidrográfica do Guaíba no Rio Grande do Sul; B) Imagem Landsat 8 (sensor OLI) da área de estudo. Composição 6R5G4B. C) Bacias Hidrográficas que desaguam no Guaíba.

Figure 1. Study site. A) Location of the Guaíba Hydrographic Region in Rio Grande do Sul; B) Landsat 8 image (OLI sensor) of the study area. Composition 6R5G4B. C) Hydrographic basins that flow into Guaíba. 
O Guaíba possui quatro classes texturais segundo o diagrama de Shepard (1954): areia, areia síltica; silte arenoso e silte argiloso. A baixa presença de argila indica que a energia do meio não é suficientemente baixa a ponto de permitir uma expressiva deposição desta fração. Portanto, a maior parcela dos sólidos suspensos argilosos que adentram no Guaíba é exportada para a Laguna dos Patos, sendo retidos os materiais sílticos e arenosos no fundo (Laybauer \& Bidone, 2001)

O Guaíba, embora seja denominado como lago pela prefeitura de Porto Alegre (DMAE, 2017) e como um rio pelo IBGE, Exército e Marinha do Brasil (CHM, 2017), é alvo de debates acadêmicos sobre sua classificação hidrodinâmica (Menegat \& Carraro, 2009; Toldo Jr. \& Almeida, 2012). Independente da denominação oficial, esse corpo d'água sofre forte pressão antrópica. Os principais impactos ambientais devem-se aos lançamentos de efluentes da cidade de Porto Alegre e da afluência das águas poluídas dos rios Gravataí e Sinos (FEPAM, 2018). Também serve de abastecimento de água para os municípios de Porto Alegre, Guaíba e Barra do Ribeiro, além de também ser utilizado em atividades de transporte de pessoas, cargas e atividades de lazer. Desde 2011, cerca de 6 milhões de pessoas utilizaram o serviço somente pelo Catamarã (JORNAL DO COMÉRCIO, 2018).

Apesar da forte pressão antrópica exercida no Guaíba, estudos de descarga líquida (Qliq) e descarga sólida em suspensão (Qss) são escassos, muitas vezes considerando dados dos rios afluentes (Vaz et al., 2006; Andrade Neto et al., 2012), porém sem medições in situ. Andrade Neto et al. (2012), realizaram a estimação de Qss entre os períodos de 2003 e 2006 realizando um ajuste de regressão entre dados de vazão dos rios afluentes e dados de turbidez do DMAE (Departamento Municipal de Água e Esgotos de Porto Alegre), sendo, portanto, uma medição indireta. Uma explicação para a escassez desses dados é causada pelo próprio trabalho de aquisição de dados, o qual demanda vários dias de levantamentos utilizando embarcação, dependente das condições meteorológicas e de uma equipe de trabalho treinada.

A estimação de Oss depende basicamente de três variáveis: área da seção, velocidade da água e concentração dos sedimentos em suspensão (CSS). A velocidade do sedimento é considerada igual à velocidade da água, estando esta variável relacionada com a Qliq. Além disso, quando a CSS estimada por amostragem pontual é utilizada para o cálculo de Qss, é preciso considerar a largura e profundidade parciais de influência do ponto de coleta, indo até a metade da distância do outro ponto de amostragem (Carvalho, 2008). Portanto, a amostragem in situ possui pouca resolução vertical (Zaleski \& Schettini, 2006).

Do mesmo modo, o trabalho em laboratório para processamento das amostras requer muito tempo a partir da amostragem inicial e o resultado final do levantamento (Zaleski \& Schettini, 2006). Portanto, esses diversos fatores citados produzem grandes limitações para estimar espaço-temporalmente a Qss e ter uma rede de monitoramento dessa variável.

Umaalternativa para o cálculo da Qss éo uso de equipamentos tipo PACD (perfilador acústico de correntes por Doppler). Esses sensores são utilizados para medir a velocidade das partículas em suspensão na água através do Efeito Doppler e consequentemente quando integrada a área da seção, a Qliq. Estes equipamentos são amplamente utilizados em estudos hidrológicos e oceanográficos (Ávila et al., 2014). Também permitem estimar a CSS, uma vez que a medida de retroespalhamento acústico (RA) do sinal do sensor é proporcional à quantidade de partículas na água (Gartner, 2004; Zaleski \& Schettini, 2006; Ávila et al., 2014).

Uma das vantagens deste equipamento é a obtenção de inúmeros perfis verticais consecutivos de velocidades de correntes e RA em toda a coluna de água, resultando em dados com excelente resolução espacial e temporal (Zaleski \& Schettini, 2006). Para estimar Qss com PACD, estes sensores possuem uma vantagem quando comparados a outros métodos, pois medem Qliq diretamente, a qual é uma variável de entrada para o cálculo de Qss. Dessa forma, a utilização de um PACD diminuí consideravelmente o tempo de trabalho, pois além de fornecer uma variável de entrada (Qliq), diminui o tempo de coleta em campo e as análises em laboratório para estimar 
CSS.

No entanto, o processo de conversão da intensidade de RA para CSS não é simples. As perdas de transmissão acústica de feixe de propagação e atenuação devem ser contabilizadas corretamente na estimação de CSS (Gartner, 2004). Esse efeito é removido por equações fornecidas pelo manual do equipamento, variando de acordo com as especificações técnicas de cada equipamento (descrição completa do método em: Gartner, 2004 Zaleski \& Schettini, 2006; Guerrero et al., 2011; Ávila et al., 2014).

O objetivo deste trabalho é gerar um panorama da hidrodinâmica e transporte de sedimentos do Rio Guaíba. Para isso foram estimadas as Qliq e Qss utilizando um sensor $\operatorname{PACD}(1,5 \mathrm{MHz})$. Foi criada uma equação de calibração do PACD para estimar a CSS e Qss no Guaíba. Ainda, objetiva comparar a Qliq medida com a soma de Qliq dos rios tributários, com oscilações de nível da água, direção e intensidade dos ventos deste ambiente.

\section{Material e métodos}

\subsection{Trabalho de campo e coleta dos dados}

Foram realizadas 22 campanhas de medições de descarga líquida com o uso de um PACD (em inglês: ADCP), no período entre junho de 2014 e janeiro de 2017. Todas as medições desse projeto foram realizadas na seção transversal da Ponta do Gasômetro, considerado o início do Guaíba.

As demais medições (09/2015, 2016 e 01/2017) de PACD foram feitas na Ponta do Gasômetro e eventualmente nas seções Ponta do Dionísio e Ponta Grossa (Fig. 2), a fim de comparar a vazão medida nas 3 seções. Este procedimento não foi realizado em todas as campanhas por indisponibilidade de tempo.

O PACD utilizado foi um SONTEK $1,5 \mathrm{MHz}$, com sistema de rastreamento do fundo (em inglês, Bottom Tracking), com GPS acoplado para definir o posicionamento na seção. O instrumento possui três transdutores orientados $25^{\circ}$ em relação ao eixo vertical e deslocados $120^{\circ}$ entre si, capaz de realizar medições de até $23 \mathrm{~m}$ de profundidade mais uma distância em branco (Sontek, 2000). Esse instrumento tem resolução vertical máxima de $50 \mathrm{~cm}$.

Para as medições de Qliq, todos os critérios adotados para obter os dados atenderam os parâmetros de qualidade sugeridos pelo fabricante (Sontek, 2000), e por agências reguladoras de recursos hídricos como a Agência Nacional de Águas (ANA), Companhia de Pesquisas de Recursos Minerais (CPRM) e Serviço Geológico dos Estados Unidos (USGS). Por exemplo, os procedimentos de calibração da bússola, cuidados com a navegação durante as travessias e número de travessias consecutivas foram implementados em campo.

$\mathrm{Na}$ seção hidrométrica da Ponta do Gasômetro, utilizada como um ponto de controle foram realizadas pelo menos quatro travessias consecutivas (Fig. 2). Caso uma das travessias apresentasse uma diferença significativa da vazão em relação às outras, maior que 5\%, então seriam realizadas mais travessias para verificação. Nas seções da Ponta do Dionísio e da Ponta Grossa foram realizadas uma ou duas travessias. Esse procedimento foi adotado devida a grande distância entre os locais e à grande largura da seção, o que tornou inviável a realização de 4 travessias nas seções mais ao sul em um mesmo dia.

Para estimar Qss, foram realizadas oito campanhas de coleta de sedimentos em suspensão nas datas indicadas na tabela 1, distribuídas entre setembro de 2015 e janeiro de 2017, totalizando 94 amostras coletadas. Nestas mesmas datas também foram realizadas as medições de Qliq.

Foi adotado o método de coleta pontual de CSS (Carvalho, 2008), utilizando uma garrafa Van Dorn (Van Dorn, 1957) horizontal com capacidade de 2 litros. A quantidade de amostras coletadas na vertical era proporcional à profundidade no ponto de amostragem. Quando a profundidade permitia, foram coletadas amostras em três camadas: logo abaixo da superfície, meio e próxima ao fundo da coluna d'água.

Em cada uma das seções horizontais foram realizados pelo menos 4 pontos de coleta de água, neles o PACD ficava gravando dados enquanto a água era coletada com a garrafa, 


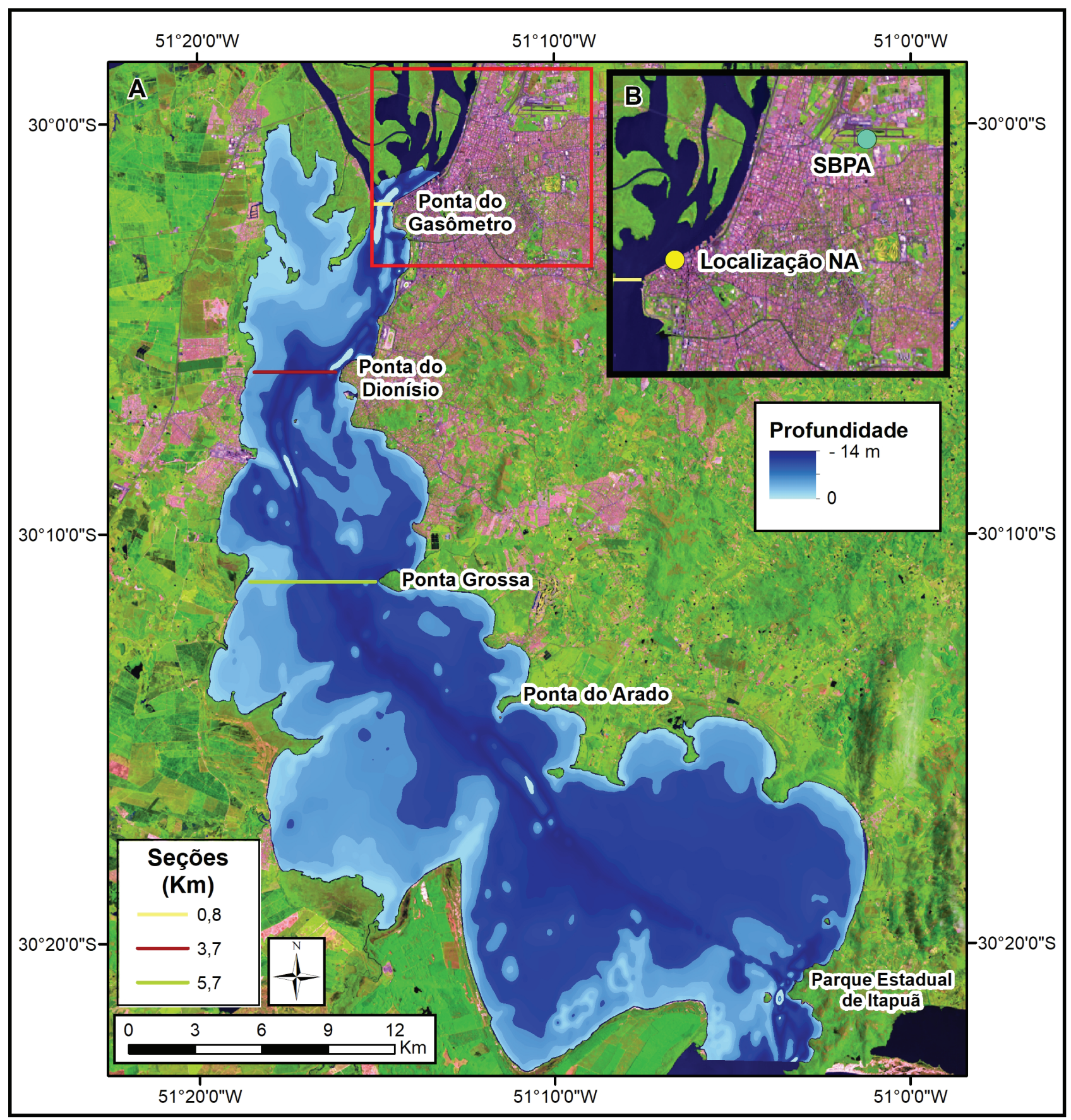

Figura 2. Área de estudo. A) Mapa das seções de monitoramento realizadas com o PADC; B) A localização da régua para medições do nível da água (NA) é localizada no ponto amarelo. O Aeroporto Internacional de Porto Alegre - Salgado Filho (SBPA) é localizado pelo ponto verde, onde foram medidos os dados de direção e intensidade dos ventos. Imagem Landsat 8 (sensor OLI) da área de estudo. Composição 6R5G4B. Batimetria conforme Nicolodi (2007).

Figure 2. Study site. Map of the monitoring sections performed with the PADC sensor. The location of the ruler for water level measurements (NA) is located at the yellow dot. The Porto Alegre International Airport - Salgado Filho (SBPA) is located by the green dot. In this place, data of intensity and direction of the winds were analyzed. Landsat 8 image (OLI sensor) of the study area. Composition 6R5G4B. Bathymetry according to Nicolodi (2007). 
em profundidades que coincidissem com as profundidades das células do PACD. Após esta etapa, eram feitas no mínimo quatro travessias para medição da descarga líquida com o PACD.

\subsection{Tratamento dos dados para estimação da concentração de sólidos em suspensão (CSS)}

Em laboratório, as 94 amostras foram filtradas pelo método gravimétrico, utilizando uma bomba de pressão a vácuo e filtros de nitrato de celulose de $45 \mu \mathrm{m}$ malha e $47 \mathrm{~mm}$ de diâmetro. Os filtros foram pesados antes e depois da filtragem, para obtenção da massa de material presente na amostra pela subtração dos pesos final e inicial.

Tabela 1. Datas de coleta de campo e quantidade de amostras utilizadas.

Table 1. Field collection dates and amount of samples used.

\begin{tabular}{c|c}
\hline Data & Amostras \\
\hline $01 / 09 / 2015$ & 21 \\
\hline $11 / 01 / 2016$ & 10 \\
\hline $27 / 01 / 2016$ & 9 \\
\hline $09 / 06 / 2016$ & 5 \\
\hline $15 / 06 / 2016$ & 10 \\
\hline $22 / 08 / 2016$ & 9 \\
\hline $22 / 10 / 2016$ & 14 \\
\hline $26 / 01 / 2017$ & 16 \\
\hline Total & 94 \\
\hline
\end{tabular}

A conversão do sinal acústico em CSS é baseada na relação existente entre a intensidade do retroespalhamento acústico (RA) e a quantidade de partículas em suspensão na coluna d'água (Ávila et al., 2014). Dessa forma, os dados de amplitude acústica de "contagens" (unidade logarítmica interna do equipamento) são transformados para potência sonora em decibéis $(\mathrm{dB})$. Para transformar a amplitude do sinal acústico em RA, a equação do sonar simplificada foi utilizada (Eq. 1):
Onde: RA - representa o retroespalhamento acústico, o qual é o sinal emitido pelos objetos ou partículas existentes no meio; EA - sinal recebido pelo transdutor; PA - perdas durante a propagação do sinal na ida e volta ao transdutor; FA - intensidade do sinal emitido pela fonte emissora.

O retroespalhamento acústico é uma medida indireta, obtida descontando-se as perdas (PA) do sinal acústico previstas do sinal do PACD (eq. 2):

\section{$P A=-20 \times \log 10(D \cos (\emptyset))-2 \times \alpha \times(D \cos (\emptyset))$}

0 ângulo do transdutor $(\phi)$ é de $25^{\circ}$, e o coeficiente de absorção (a) é a igual 0,68 (Sontek, 1997). A distância (D) se refere à profundidade de cada célula medida pelo PACD, da superfície ao fundo. Uma vez obtido o RA relativo a cada célula, a calibração consistiu em realizar um modelo de regressão da CSS in situ na mesma profundidade e localização com os dados de RA. As etapas de estimação de CSS e Qss são esquematizadas na figura 3.

$\mathrm{Na}$ análise de regressão foi testado $\circ \mathrm{R}^{2}$, significância dos coeficientes e teste KolmogorvSmirnov (K-S) para a normalidade dos resíduos. Para os testes dos coeficientes e K-S foi considerada uma significância $\alpha=0,01$.

\subsection{Cálculo da descarga sólida em suspensão (Qss)}

Primeiramente, foi calculado o RA para todo um perfil transversal medido pelo PACD. Depois, através da regressão obtida dos dados in situ e do PACD foi estimado valores de CSS para todo este perfil transversal. Após esta etapa foi calculada uma média da CSS que foi usada na fórmula abaixo, sendo assim possível calcular a Qss multiplicando pela descarga líquida (Qliq) medida pelo PADC (eq. 3).

$$
\text { Qss }=0,0864 \times \text { CSS } \times \text { Qliq }
$$




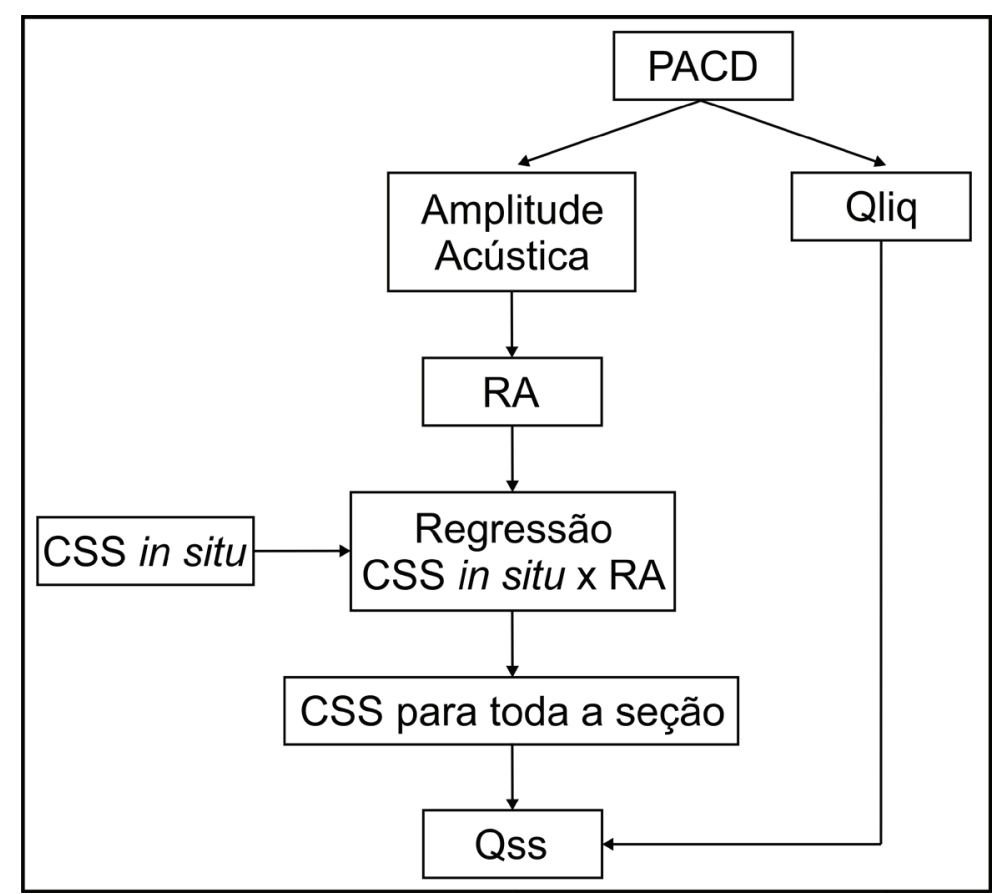

Figura 3. Etapas para estimação de CSS e Qss.

Figure 3. Steps for estimation of CSS and Qss.

\subsection{Análises realizadas}

Comparação do nível da água (NA) com a descarga líquida: O NA foi obtido através da régua do cais da Mauá, disponibilizado pelo site do Sistema de Monitoramento e Alerta de Desastres (SMAD, 2017). A localização da régua é mostrada na figura 2.

Utilização e comparação das séries temporais (1940 a 2017) de descargas líquidas dos quatro principais tributários do Guaíba (rios Jacuí, Taquarí, Caí e Sinos): adquiridas junto ao site Hidroweb da ANA (http://hidroweb.ana.gov. br/) e os dados medidos com o PACD na Ponta da Gasômetro.

Foi realizada uma expansão da série temporal pelo modelo publicado de Andrade Neto et al. (2012) para o período de 01/2013 a 09/2017. Foi comparada as variáveis CSS, e Oss estimada neste trabalho com a CSS e Qss estimada por Andrade Neto et al. (2012). Além disso, foi realizada uma comparação qualitativa dos dados de Qliq com dados METAR (Meteorological Aerodrome Report) de direção e intensidade dos ventos localizados na estação do Aeroporto Internacional de Porto Alegre Salgado Filho (Fig. 2).

\section{Resultados e discussão}

\subsection{Descargas líquidas na seção do Gasômetro}

As descargas líquidas (Qliq) medidas pelo PACD durante o período em estudo demonstraram a grande variabilidade deste sistema (Fig. 4). Foram observados valores mínimos e máximos de 407 e $14.270 \mathrm{~m}^{3} / \mathrm{s}$, respectivamente. Estes valores estão de acordo com séries históricas desta bacia hidrográfica (Vaz et al., 2006). Os valores apresentados na figura 4 referem-se às medições de descarga líquida realizadas na Ponta do Gasômetro, usada como seção de controle. O citado valor máximo foi medido no maior nível d'água alcançado $(2,7 \mathrm{~m}$, régua do Caís Mauá) durante uma das maiores cheias nos últimos 77 anos, que ocorreu em 22 de outubro de 2016. Este valor corresponde ao terceiro maior valor da série temporal dos tributários no período de 1940 - 2017.

A relação entre o NA e a Qliq foi fraca, com valor de $R^{2}$ igual a 0,55 (Fig. 5). Uma possível explicação para isto é a grande área superficial do Guaíba e a influência das oscilações de nível da Lagoa dos Patos, localizada no exutório do Guaíba. A grande extensão e largura deste 
ambiente produz uma "pista de vento" grande o suficiente, que possibilita a ação do vento local no NA e consequentemente no fluxo da água. A Lagoa dos Patos também pode variar o nível significativamente, causando um efeito de represamento das águas do Guaíba em situações de ventos de Sul (Möller et al., 2007). Dessa forma, a impossibilidade de estabelecer uma curva-chave para o Guaíba é justificada em função do baixo valor de $\mathrm{R}^{2}$.

Foi realizado um comparativo entre as séries temporais de descargas líquidas dos quatro principais tributários do Guaíba (rios Jacuí, Taquarí, Caí e Sinos) e os dados medidos com o PACD na Ponta da Gasômetro (Fig. 6). A correlação entre estes dados resultou em $R^{2}$ igual a 0,93, indicando uma forte associação entre os dados estimados de vazão nos principais afluentes e os dados medidos de vazão no Guaíba.

Os dados medidos por PACD na Ponta da Gasômetro possuem valores superiores em 84\% das amostras quando comparados com a soma dos tributários. Esse resultado era esperado pela posição das estações fluviométricas (Fig. 1), que estão localizadas no interior das bacias hidrográficas e consequentemente não englobam toda a área de drenagem que deságua no Guaíba.

\subsection{Estudo do comportamento das Qliq no interior do Guaíba}

Foram realizadas medições nas seções transversais na Ponta do Dionísio e a Ponta Grossa, além da seção de controle da Ponta do Gasômetro (Tab. 2). Essas seções estão distantes, respectivamente, 9 e $18 \mathrm{~km}$ da Ponta do Gasômetro. Pode-se observar que, apesar da grande distância, da diferença na largura e configuração batimétrica entre as seções, os valores de descarga líquida possuem uma correspondência em magnitude entre si, concordando com a continuidade do fluxo principal no sentido $\mathrm{N}-\mathrm{S}$.

Embora os valores de descarga líquida entre as seções sejam semelhantes, o alargamento das seções da Ponta do Dionísio e Ponta Grossa reduz a velocidade do escoamento da água. Comparando especificamente as seções da
Ponta do Gasômetro e Ponta Grossa (Fig. 7), é possível observar que os valores de velocidade da corrente se reduzem a aproximadamente a metade nas áreas nas áreas mais largas.

As maiores velocidades são encontradas no canal de navegação e áreas imediatamente adjacentes. O canal, região com maiores profundidades, oferece menor resistência ao escoamento d'água. A seção do Gasômetro é a mais estreita do Guaíba (Tab. 2) e apresenta as maiores velocidades de escoamento. As correntes acima de $40 \mathrm{~cm} / \mathrm{s}$, observados em $74 \%$ dos perfis de monitoramento, geram tensões de cisalhamento suficiente para construção de dunas subaquosas (Ashley, 1990), as quais foram mapeadas através de perfilagem sísmica nas proximidades da Ponta do Gasômetro (Scottá et al., 2019), indicando correspondência direta entre os dados medidos de corrente e o mapeamento da morfologia de fundo do Guaíba.

Na seção da Ponta do Dionísio e da Ponta Grossa, as maiores velocidades também são registradas nas áreas no canal, porém com menor velocidade e consequentemente menor competência do transporte de sedimentos mais grossos. Esse comportamento foi relatado previamente por outros autores (Bachi et al., 2000, Toldo Jr. et al., 2000; Nicolodi, 2007), que observaram que o regime fluvial dos tributários perde a competência como agente transportador ao ingressar no Guaíba. Na data de 15/09/2015 foram registradas descargas (Qliq) de 1.767 $\mathrm{m}^{3} / \mathrm{s}$, com velocidades de fundo entre 9 e 24 $\mathrm{cm} / \mathrm{s}$, menores que aquelas a montante, porém suficientes para o transporte de arrasto do sedimento arenoso.

Também se observa um comportamento tridimensional do escoamento, ou seja, em toda a coluna d'água, demonstrando um padrão de circulação fluvial no corpo hídrico. Esse resultado difere das discussões de Menegat \& Carraro (2009), que propõem fluxo bidimensional, apenas na superfície das águas do Guaíba.

Em 22/10/2016 foi registrada a condição "máxima" de Qliq no Guaíba (Fig. 7). Os valores de velocidade no canal superaram 220 e 140 $\mathrm{cm} / \mathrm{s}$ nas seções da Ponta Grossa e Ponta do Dionísio, respectivamente. Nessas condições hidrodinâmicas a descarga apresenta 


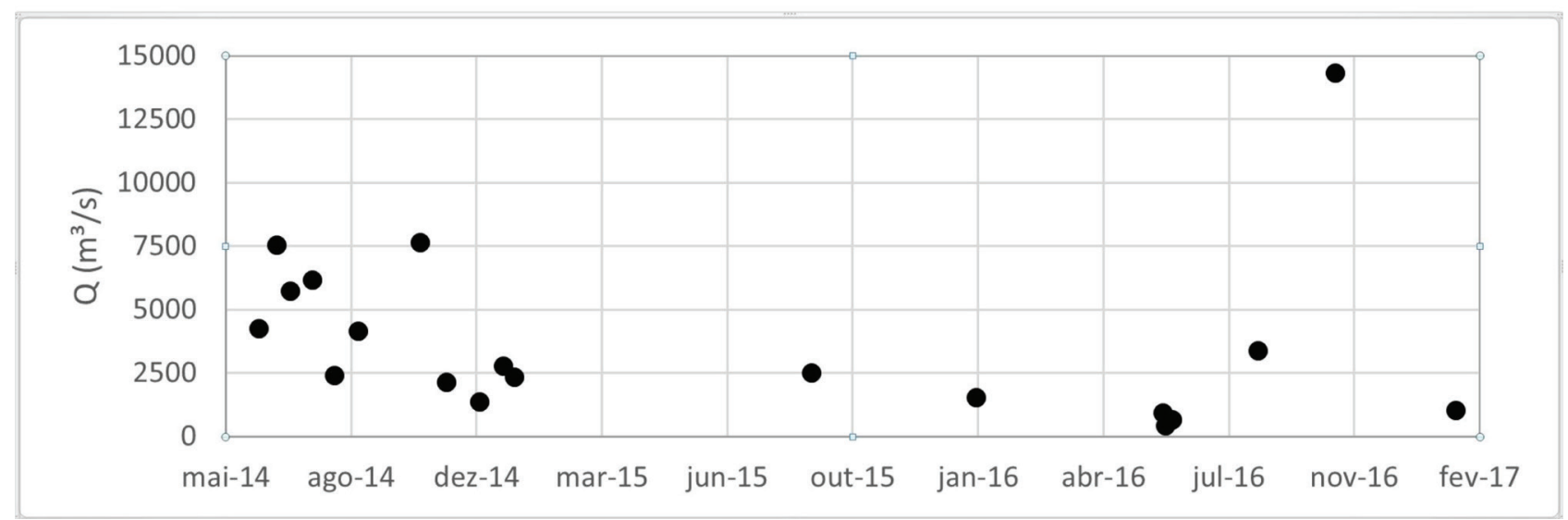

Figura 4. Qliq medidas na Ponta do Gasômetro durante o período em estudo.

Figure 4. Qliq measured at the Ponta do Gasômetro during the study period.

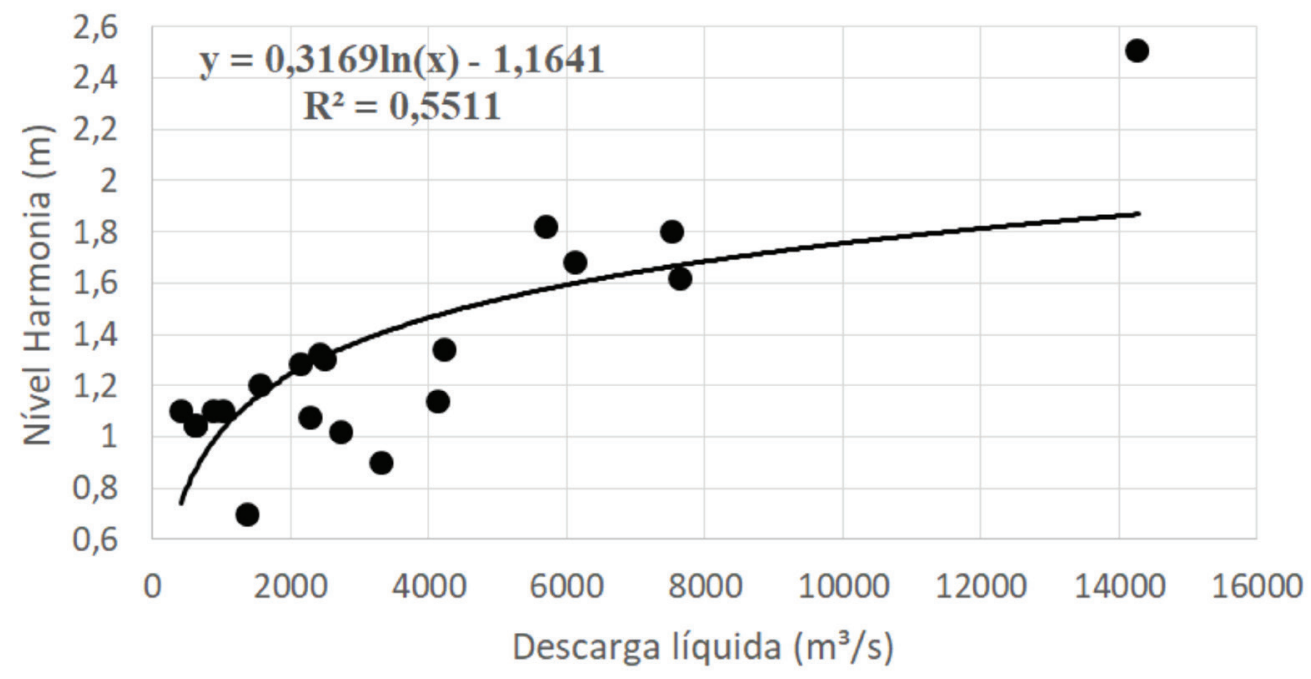

Figura 5. Relação entre NA e Qliq.

Figure 5. Relationship between NA and Qliq.

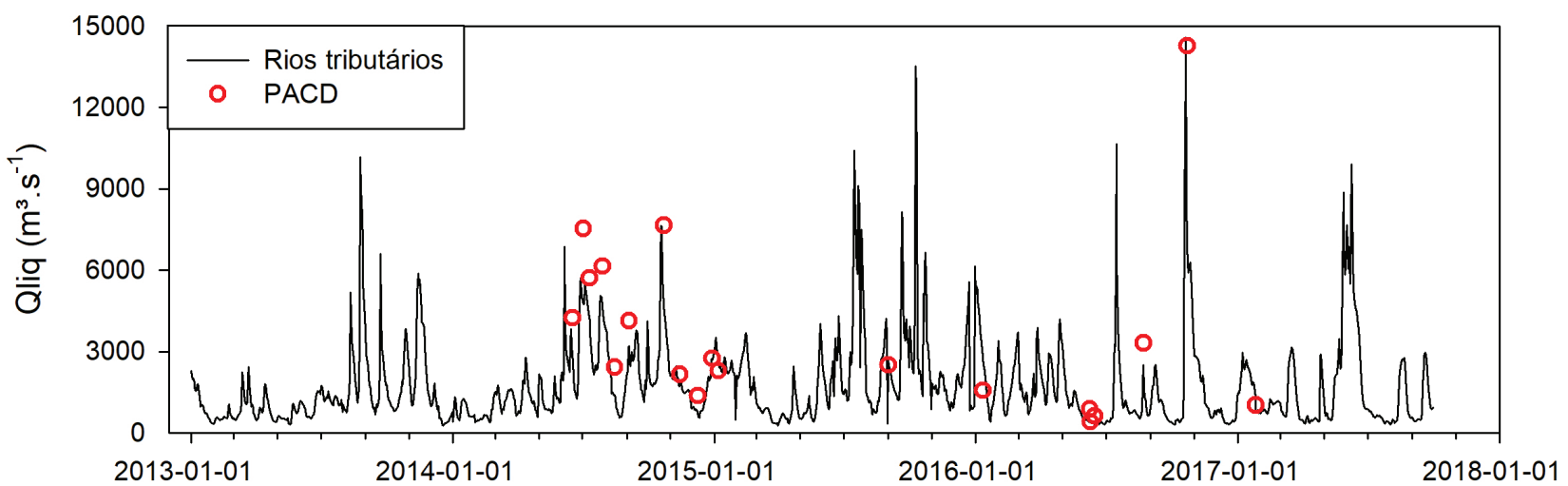

Figura 6. Comparação entre os dados de Qliq dos 4 principais tributários do Rio Guaíba (linha em preto) e dados de Qliq medidos na seção Ponta do Gasômetro (pontos em vermelho).

Figure 6. Comparison between the Qliq data of Guaiba River 4 main tributaries (black line) and Qliq data measured in the Ponta do Gasômetro section (red points). 
Tabela 2. Qliq $\left(\mathrm{m}^{3} / \mathrm{s}\right)$ nas 3 seções transversais no rio Guaíba. Table 2. Qliq $\left(\mathrm{m}^{3} / \mathrm{s}\right)$ in the 3 cross sections in the Guaiba river.

\begin{tabular}{ccccccc}
\hline & $\begin{array}{c}\text { Largura } \\
\text { seção }\end{array}$ & $01 / 09 / 2015$ & $22 / 08 / 2016$ & $22 / 10 / 2016$ & $\begin{array}{c}26 / 01 / 201 \\
7\end{array}$ \\
\hline $\begin{array}{c}\text { Ponta } \\
\text { Gasômetro }\end{array}$ & $0,8 \mathrm{Km}$ & 2.496 & 3.311 & 14.270 & 1.025 \\
\hline Ponta Dionísio & $3,7 \mathrm{Km}$ & 1.767 & 3.689 & 14.190 & --1. \\
\hdashline Ponta Grossa & $5,9 \mathrm{Km}$ & --- & --- & 14.040 & 749 \\
\hline
\end{tabular}

capacidade para remobilizar e transportar os sedimentos arenosos de fundo, inclusive as frações de tamanho cascalho e seixo, mostrando grande competência de transporte da carga de sedimentos grossos em situações de valores elevados de Qliq.

Nas áreas periféricas das seções Ponta do Dionísio foram registrados valores acima de 40 $\mathrm{cm} / \mathrm{s}$, condição crítica para erosão e transporte dos sedimentos arenosos. Esses dados indicam que o transporte de areia nas áreas periféricas das seções mais largas ocorre apenas em situações de descarga líquida elevada. Uma análise da série temporal dos rios tributários indica que vazões acima de $12.000 \mathrm{~m}^{3} / \mathrm{s}$ ocorreram apenas dez vezes no período 1940-2017.

\subsection{Influência dos ventos na inversão de fluxo no Guaíba}

Os ventos registrados pela estação meteorológica analisada (Fig. 2) no período das medições apresentaram predomínio de orientação leste, sendo a direção predominante nessa região (Livi, 1998; Camargo, 2002; Nicolodi, 2007). Duas situações de inversão das correntes na Ponta do Gasômetro foram registradas em 01/09/2015 e 13/01/2016, sendo relacionadas com ventos nos quadrantes S e SE. A intensidade dos ventos média das últimas 4 horas à realização da medição foi de 5,6 e 6,3 m/s para as respectivas datas.

$\mathrm{Na}$ data de 01/09/2015 os valores variaram de $-60,3$ à 410,6 m³ $/ \mathrm{s}$. A inversão do fluxo observada no dia 13/01/2016, ocorrida com maior intensidade, foi registrada de forma progressiva, com valores positivos nas duas primeiras travessias e que gradualmente foram se reduzindo até o valor de $-341 \mathrm{~m}^{3} / \mathrm{s}$. A estratificação das correntes também pode ser observada na figura 8. Os valores de corrente negativos (para $\mathrm{N}$ ) ocorreram inicialmente na superfície, pelo atrito com o vento, e nas laterais da seção, pela baixa velocidade nas margens. As áreas mais profundas, embora tenham reduzido a velocidade do fluxo nas duas últimas medições, mantiveram o sentido de escoamento preferencial Norte - Sul. Na mesma data, a Qliq dos tributários apresentou um valor de 2.455 $\mathrm{m}^{3} / \mathrm{s}$.

Situações de inversão de fluxo no Guaíba foram documentadas em trabalhos prévios e relacionadas com a ocorrência de ventos de quadrante Sul (DNAEE ,1983; Casalas \& Cybis, 1985; Nicolodi, 2007; CHM, 2017). A ocorrência de ventos de quadrante sul está na faixa de 12\%, com a predominância de ventos Se SE (Livi, 1998; Nicolodi, 2007). O vento S pode ser responsável por represar a água e reduzir os valores de Oliq no Guaíba, especialmente nas áreas a sul que possuem maior pista para a ação do vento. Segundo o relatório de correntes do DNAEE (1983), de 8.779 pontos medidos no Guaíba, apenas 15\% das medições apresentaram inversão de fluxo, os quais ocorreram principalmente na seção de Itapuã e seções intermediárias. Nenhuma situação de inversão de fluxo foi medida na Ponta do Gasômetro no citado relatório.

A inversão de fluxo, principalmente na área norte do Rio Guaíba, é eventual pela baixa frequência de ventos de quadrante $S$. Além disso, os ventos devem ter intensidade e duração suficiente para forçar a inversão, como demonstrado na Figura 8. A inversão também está associada a situações de baixas Qliq, ou seja, sob condições de correntes com menores velocidades. 


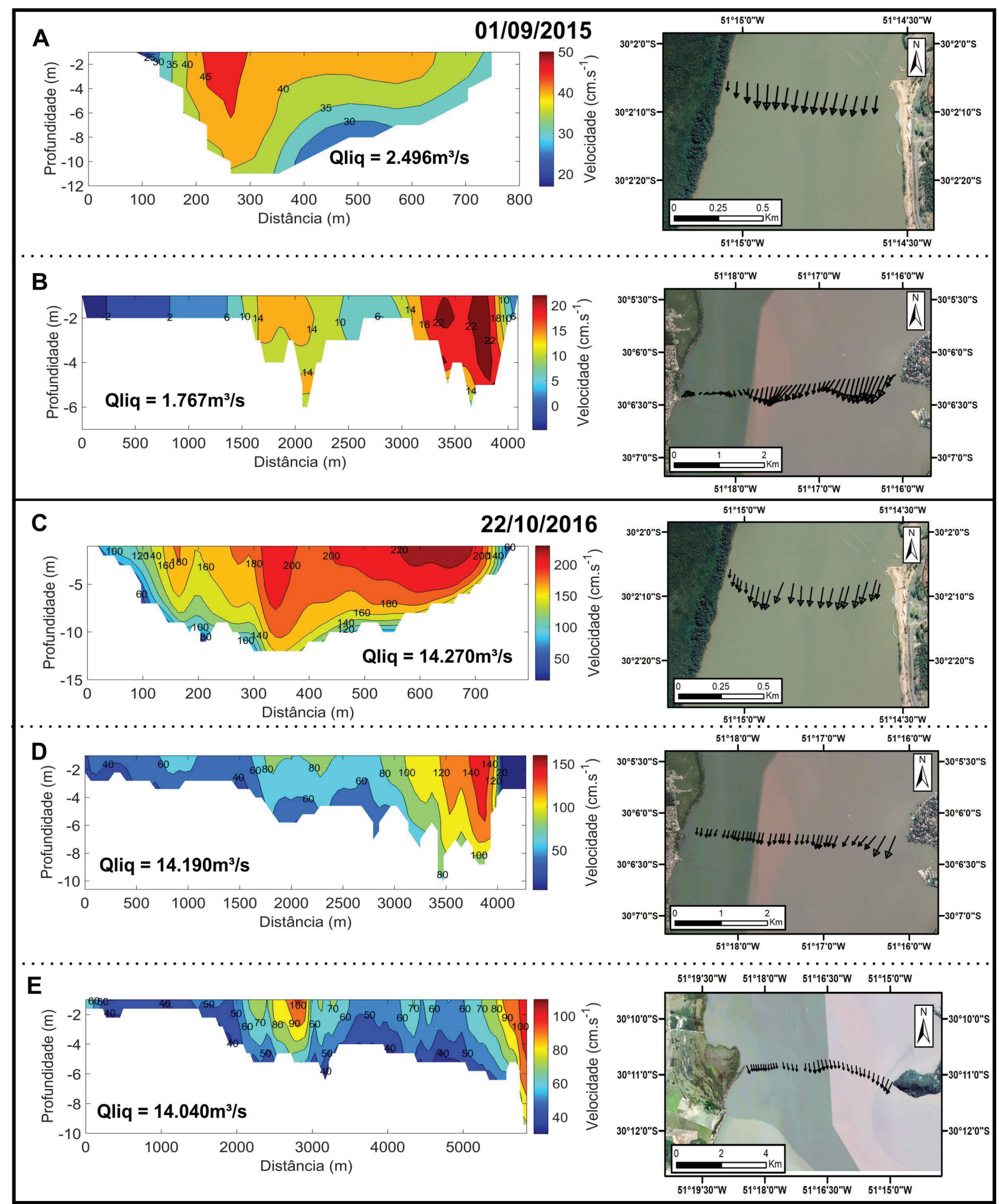

Figura 7. Perfis de medições das velocidades e o mapa de localização das seções com as correntes vetorizadas na direção preferencial do escoamento. A) Ponta do Gasômetro; B) Ponta do Dionísio; C) Ponta do Gasômetro; D) Ponta do Dionísio; E) Ponta Grossa.

Figure 7. Profiles of velocity measurements and the location map of the sections with the vectored currents in the main flow direction. A) Ponta do Gasômetro; B) Ponta do Dionísio; C) Ponta do Gasômetro; D) Ponta do Dionísio; E) Ponta Grossa. 


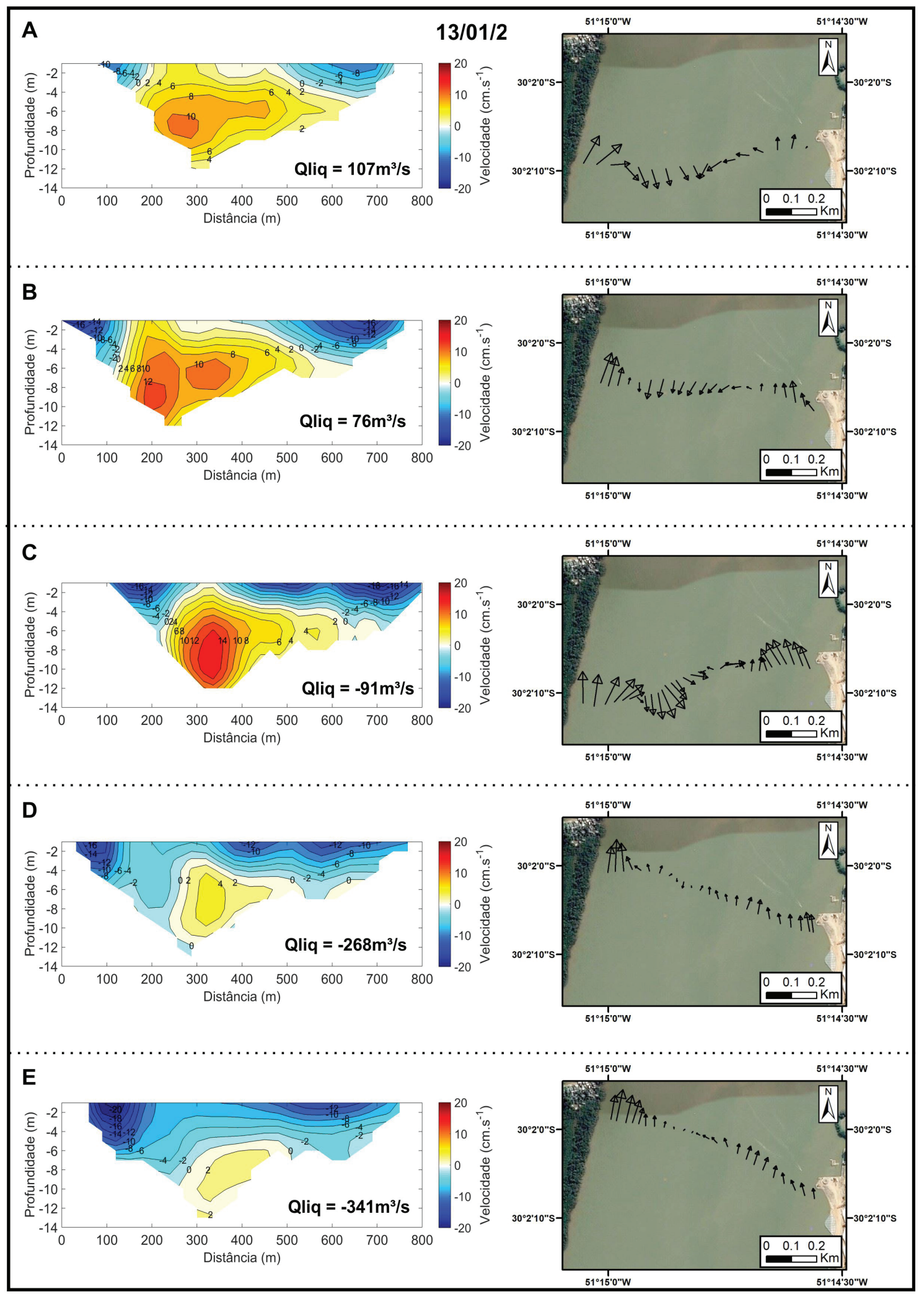

Figura 8. Registros da inversão do fluxo em 13/01/2016. Cores quentes representam o sentido predominante Norte-Sul e as cores frias representam fluxo Sul-Norte (a esquerda). Mapa das seções com as correntes vetorizadas (a direita). A) Medição 1; B) Medição 2; C) Medição 3; D) Medição 4; E) Medição 5.

Figure 8. Flow inversion records on 01/13/2016. Warm colors represent the predominant North-South direction and the cold colors represent South-North flow (the left). Map of sections with vectorized currents (right). A) Measurement $1 ; B$ ) Measurement 2; C) Measurement 3; D) Measurement 4; E) Measurement 5. 


\subsection{CSS e Qss}

Entre as 94 amostragens de CSS in situ, quatro foram excluídos por problema nos dados do PACD. O resultado de ajuste da equação pode servisualizado na figura 9, mostrando uma relação exponencial com $R^{2}$ de 0,7 . Estudos mostraram valores semelhantes para o coeficiente de determinação $\left(R^{2}\right)$ para outras regiões (Gartner, 2004; Zaleski \& Schettini, 2006; Ávila et al., 2014), sendo considerado aceitável para a estimação de CSS. A regressão apresentou significância estatística para os interceptos e normalidade dos resíduos $\operatorname{com} \alpha=0,01$.

Foi encontrada uma predominância de valores entre 20 a $40 \mathrm{mg}^{\mathrm{I}^{-1}}$, e uma quantidade

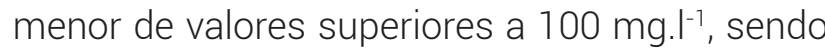
valores esperados para esse ambiente de acordo com Andrade Neto et al. (2012). Uma das dificuldades dessa pesquisa foi coletar dados com concentrações de $40 \mathrm{mg}^{\mathrm{I}^{-1}}$ a $100 \mathrm{mg}^{-\mathrm{I}^{-1}}$ Valores acima de $100 \mathrm{mg}^{-1} \mathrm{I}^{-1}$ foram encontrados em apenas três campanhas realizadas.

Embora o manual do equipamento (Sontek, 1997) sugira um valor acima de 1000 mg.l ${ }^{1}$ como limite para a aquisição dos dados com qualidade, foi possível observar maior geração de resíduos em concentrações maiores que 100 mg.l ${ }^{-1}$. Resíduos da regressão em elevadas concentrações também foi encontrado em trabalhos que tiveram o mesmo objetivo de calibração de PACD em outros corpos hídricos (Gartner, 2004; Zaleski \& Schettini, 2006; Ávila et al., 2014) . A acurácia nas situações de maiores concentrações é incerta e sugere-se que mais amostras devem ser coletadas para refinamento do modelo de regressão.

Através da equação exponencial obtida foi possível estimar a CSS para toda uma seção realizada com PACD. Os dados de CSS deste trabalho possuem forte associação linear (Fig. 10) com os resultados gerados por Andrade Neto et al. (2012). Essa relação mostra que as variações ao longo da série são muito próximas. Os valores de CSS quando comparados entre os métodos tiveram diferença média de 12,75 mg. ${ }^{-1}$, com valores mínimo e máximo de 2,52 mg..$^{l^{-1}}$ (amostra 10) e 25,88 mg.l-1 (amostra 18). Embora os métodos utilizados apresentarem resultados semelhantes, a CSS obtida com o PADC apresentou valores menores que os resultados obtidos pelo método de Andrade Neto et al. (2012) em todas as amostras, com exceção da amostra 18.

A metodologia proposta por Andrade Neto et al. (2012) possui calibração do modelo apenas no ponto de captação da Estação de Tratamento de Esgoto no Bairro Menino Deus, distante 400 m da margem do Guaíba e profundidade superior a $2 \mathrm{~m}$. Por não se localizar no canal de navegação, os valores de CSS e Qss poderiam estar subestimados nesta metodologia. Porém, a comparação com os dados de PACD, medidos ao longo de toda a seção da Ponta do Gasômetro, não mostra subestimação da série, visto que os dados são semelhantes e que a estimação de CSS e Qss de Andrade Neto et al. (2012) é válida.

Os valores de Qss dos dados de PACD apresentaram valores mínimos e máximos de 0,77 a 118,13 t/dia (Fig. 10). O valor máximo de 118,130 t/dia corresponde à data de 22/10/2016 na condição de máxima. Apesar disso, a acurácia desse valor não pode ser avaliada pelos maiores resíduos gerados pelo modelo em situações de alta CSS. Panorama semelhante, com maiores resíduos em alta CSS, é registrado no modelo de Andrade Neto et al. (2012) para o Guaíba. Essa condição de maior indeterminação em maiores CSS é influenciada por diversos fatores além da Qliq, como efeitos sazonais, processos de exaustão, condições do uso do solo e precipitação pluvial (Batalla \& Sala, 1994; Rovira \& Batalla, 2006; Oeurng et al., 2010).

A Qss apresenta valores próximos entre os métodos devido a forte correlação da Qliq (Fig. 11). As maiores diferenças entre os métodos estão nos valores de CSS, que também apresentam forte associação linear $(R=0,78$, Fig. 10). O valor médio de Qss da série temporal 01/2013 - 09/2017 pelo modelo de Andrade Neto et al. (2002) é de 7,58 t/dia, com valores mínimos e máximos de 0,65 a 98,24 t/dia. Uma característica importante sobre o Guaíba é ter maior contribuição de Qss em condições de descarga moderadas, sendo uma característica que distingue esse sistema de outros sistemas fluviais (Andrade Neto et al., 2002), que possuem a maior porcentagem de transporte de Qss concentradas em condições de enchente. 


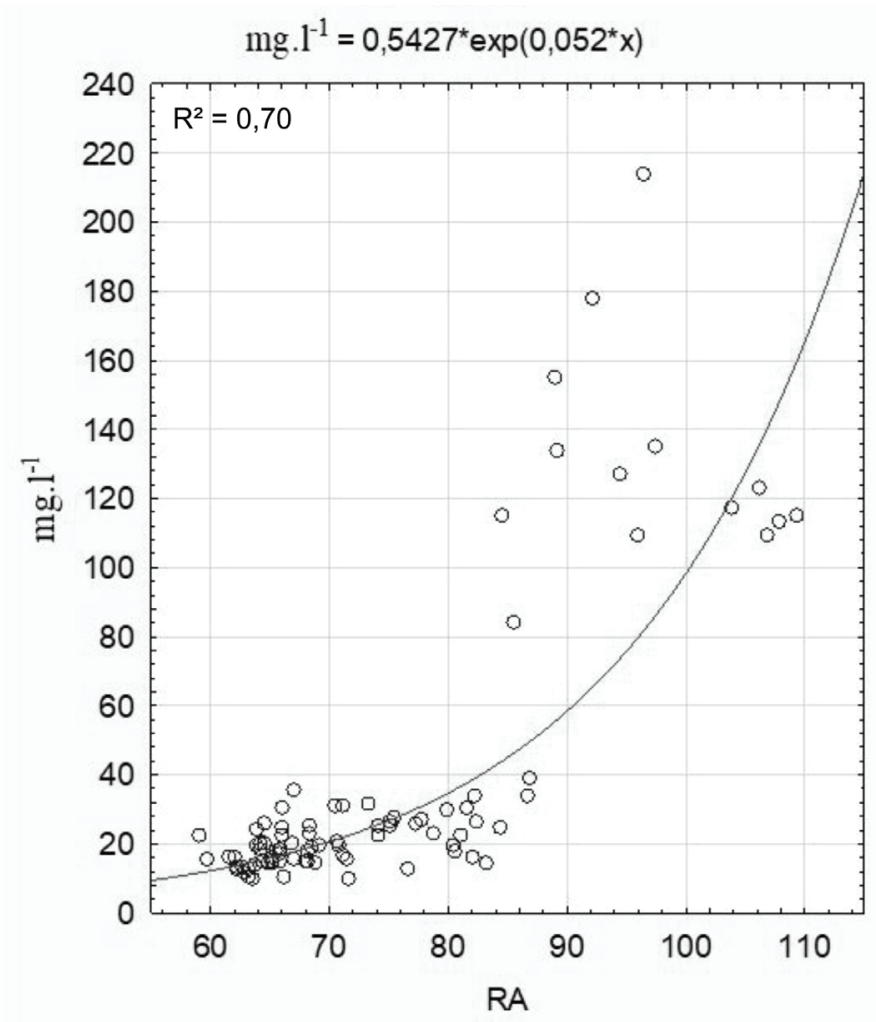

Figura 9. Relação entre a CSS (mg..$\left.^{-1}\right)$ e RA.

Figure 9. Relationship between CSS $\left(\mathrm{mg}^{\left.-\mathrm{I}^{-1}\right)}\right.$ and RA.

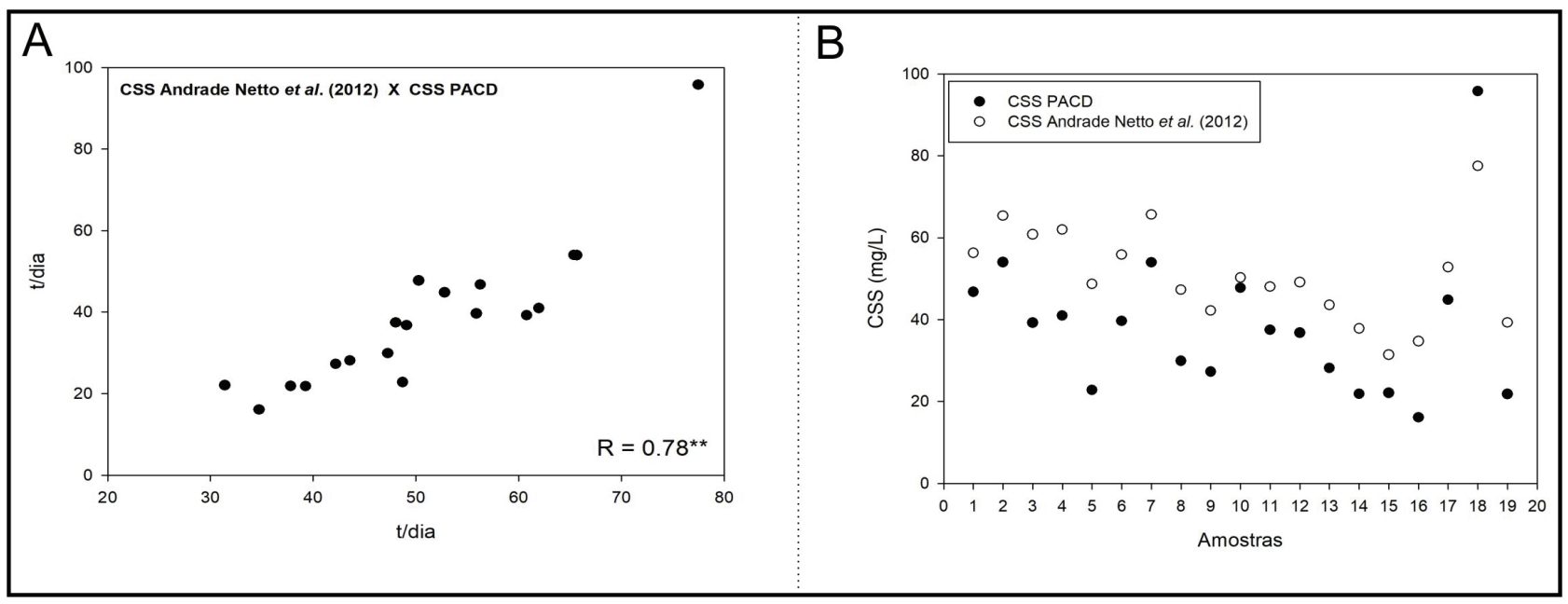

Figura 10. Análise de dados. A) Correlação da CSS (mg/L-1) das amostras coletadas por PACD comparadas com os dados de Andrade Neto et al. (2012). B) Diferença da CSS (mg/L-1) das amostras coletadas por PACD comparadas com os dados de Andrade Neto et al. (2012).

Figure 10. Data analysis. A) CSS correlation $\left(\mathrm{mg}^{\prime} \mathrm{L}^{-1}\right)$ of the samples collected by PACD compared with the data of

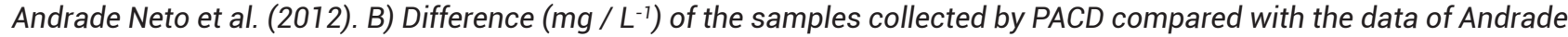
Neto et al. (2012). 

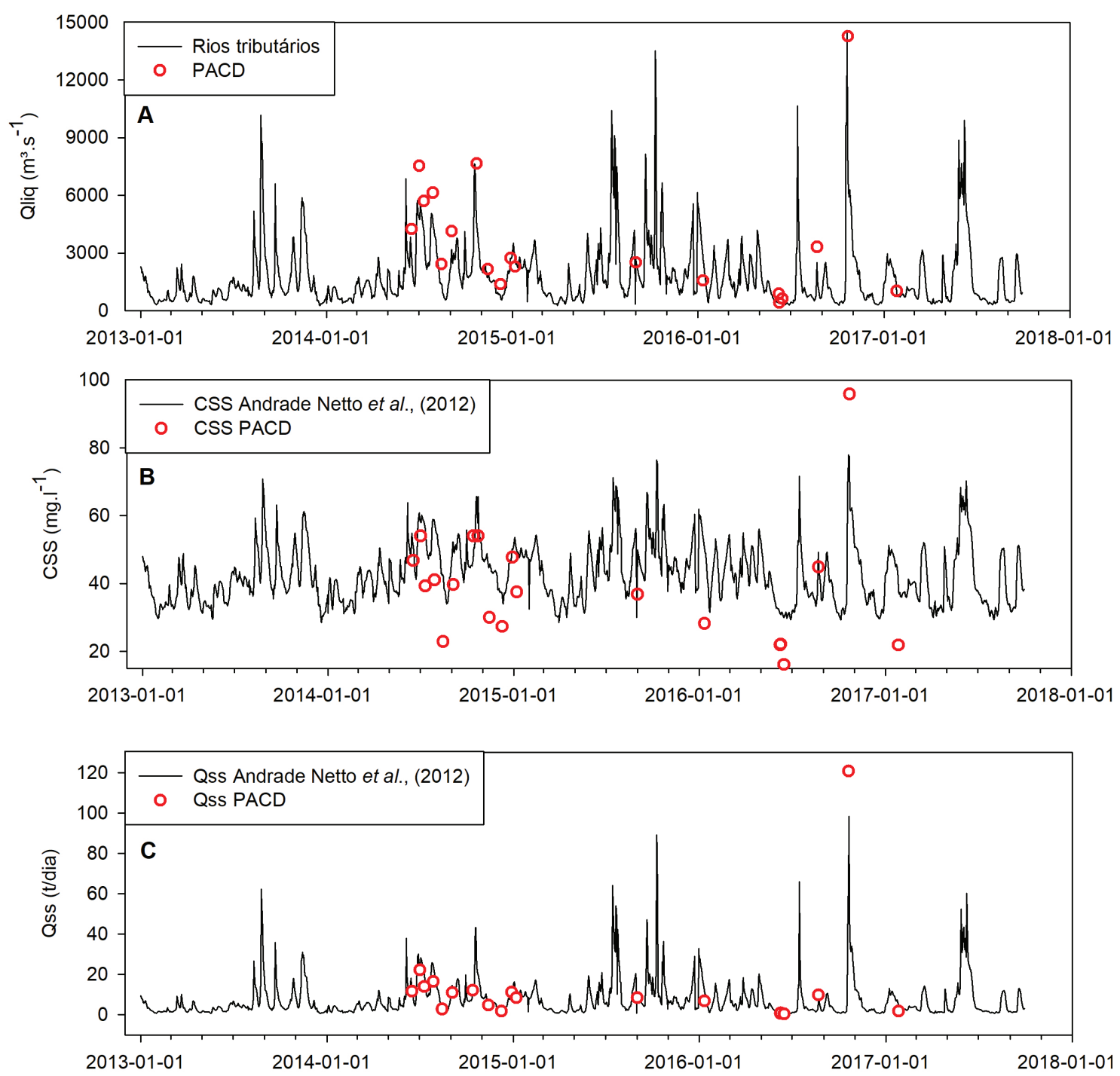

Figura 11. Séries temporais e dados de PACD das variáveis. A) Qliq; B) CSS; C) Qss.

Figure 11. Time series and PACD data of the variable: A) Qliq; B) CSS; C) Qss.

\section{Conclusões}

Foi possível realizar um estudo abrangente sobre as variáveis Qliq e Qss no Guaíba. Os dados de Qliq medidos possuem valores muito próximos a soma dos dados de vazão estimados para os rios Jacuí, Taquarí, Caí e Sinos, apresentando forte correlação com coeficiente de 0,93. As descargas líquidas recebidas pelo Guaíba apresentam um escoamento preferencial para sul orientado pelo canal de escoamento.

A região de transição entre diferentes corpos hídricos naturalmente não possibilita a aplicação da curva chave. Isto foi observado no Guaíba na tentativa de ajuste da referida curva entre a vazão e a régua localizada no Cais Mauá.
A relação entre o NA e a descarga líquida foi fraca devido as oscilações de nível causadas principalmente pelo vento nesse sistema.

Ademais, foi possível investigar o comportamento, das Qliq, das seções na parte interna do Guaíba (Ponta do Dionísio e Ponta Grossa) em relação à seção de entrada (Ponta do Gasômetro) demonstrando comportamento semelhante entre elas.

A área da entrada do Guaíba apresenta velocidades de correntes suficientes para transporte e erosão dos sedimentos arenosos. As seções mais largas (seções da Ponta do Dionísio e Ponta Grossa) apresentam competência para transporte como arrasto de fundo. Nestas duas seções, apenas condições de cheias com altas 
descargas líquidas são suficientes para provocar erosão e transporte do sedimento arenoso e ocorrem de forma esporádica. As maiores velocidades se encontram na região do canal independente da seção analisada.

A ação do vento provoca eventualmente a inversão de fluxo do sistema Guaíba. Duas situações de inversão foram registradas nos perfis de corrente medidos na entrada do Guaíba e foram relacionadas com a ocorrência de ventos nos quadrantes S e SE.

Este estudo também expõe a possibilidade de calibração do sensor PACD para estimar CSS e Qss no Guaíba e de estimar a quantidade de volume de sedimentos transportados para a bacia hidrográfica do Guaíba.

Trabalhos futuros devem focar na compreensão do comportamento do transporte de sedimentos em condições de maiores descargas líquidas e sólidas. Portanto, sugerese que a coleta de dados seja realizada nessas condições. Outro possiblidade de trabalho é a investigação detalhada da descarga líquida e sólida na seção de Itapuã, local limite do Guaíba com a Laguna dos Patos.

Agradecimentos. Ao professor Dr. Davi da Motta Marques pelo empréstimo do PACD, ao CNPq e CAPES/CiMar pela concessão de bolsa aos primeiros autores. Os autores agradecem ainda aos alunos de pós-graduação do PPGGEO que auxiliaram nas campanhas realizadas e ao CECO/UFRGS pela disponibilização da infraestrutura para coleta e processamento dos dados. Esse trabalho é parte constituinte da Tese de doutorado do primeiro autor.

\section{Referências}

Alvares C.A., Stape, J.L., Sentelhas, P.C., Gonçalves, J.L.M. \& Sparovek, G. 2013. Köppen's climate classification map for Brazil. Meteorologische Zeitschrift, 22(6): 711-728.

ANA. Agência Nacional de Águas. 2007. Evolução da rede hidrometeorológica nacional. Superintendência de Administração da Rede Hidrometeorológica. Brasília, 15p. Andrade Neto, J.S., Rigon, L.T., Toldo Jr., E.E. \& Schettini, C.A. 2012. Descarga sólida em suspensão do sistema fluvial do Guaíba, RS, e sua variabilidade temporal. Pesquisas em Geociências, 39(2): 161-171.

Ashley, G.M. 1990. Classification of lage-scale subaqueous bedforms: a new look at an old problem. Journal of Sedimentary Petrology, 60 (1): 160-172.

Ávila, R.A., Möller Jr., O.O. \& Andrade, M.M. 2014. Uso de um ADCP para estimar concentrações de material particulado em suspensão para o estuário da Lagoa dos Patos, Brasil. Revista Brasileira de Recursos Hídricos, 19(2): 299309.

Bachi, F.A., Barboza, E. G. \& Toldo, E. E. 2000. Estudo da sedimentação do Guaíba. Ecos, 17: 32-35.

Batalla, R.J. \& Sala, M. 1994. Temporal variability of suspended sediment transport in a Mediterranean sandy gravel-bed river. Variability in Stream Erosion and Sediment Transport. IAHS Pubi. no. 224. Disponível em: http://hydrologie.org/redbooks/a224/ iahs_224_0299.pdf. Acesso em: 18 ago. 2018. Camargo, O.A. 2002. Atlas Eólico: Rio Grande do Sul. Porto Alegre, Secretaria de Minas e Comunicações (SEMC). 70p.

Carvalho, N.O. 2008. Hidrossedimentologia Prática. Rio de Janeiro, Editora Engenho Novo, 599p.

Casalas, A. \& Cybis, F. 1985. Modelo matemático de circulação e de qualidade das águas do estuário do Rio Guaíba. In: SIMPÓSIO BRASILEIRO DE HIDROLOGIA E RECURSOS HÍDRICOS, São Paulo. Anais...São Paulo, p. $419-432$.

CHM. Centro de Hidrografia da Marinha. De Itapuã a Porto Alegre. 2013. Disponível em: <https:// www.mar.mil.br/dhn/chm/box-cartas-raster/ raster_disponiveis.html>. Acesso em: 09 jan. 2017.

CPRM. Serviço Geológico do Brasil. 2020. Atlas Pluviométrico do Brasil. Disponível em: <https://www.cprm.gov.br/publique/ Hidrologia/Mapas-e-Publicacoes/AtlasPluviometrico-do-Brasil-1351.html>. Acesso em: 27 maio 2020.

Delaney, P.J.V. 1965. Fisiografia e geologia da superfície da planície costeira do Rio Grande do Sul. Porto Alegre, Publicação Especial da 
Escola de Geologia, UFRGS, 6: 105p.

Donohue, I. \& Molinos, J.G. 2009. Impacts of Increased Sediment Loads on the Ecology of Lakes. Biol. Rev. of the Cambridge Philosophical Society, 84(4):517-531.

DMAE. Departamento Municipal de Água e Esgotos. Lago Guaíba. 2017. Disponível em: <http://www2.portoalegre.rs.gov.br/dmae/ default.php?p_secao=197>. Acesso em: 18 maio 2017.

DNAEE. Departamento Nacional de Águas e Energia Elétrica. 1983. Mecânica de Correntes do Guaíba: Relatório Síntese. Ministério das Minas e Energia, Porto Alegre, 61p.

Do, H.X., Gudmundsson, L., Leonard, M. \& Westra, S. 2018. The Global Streamflow Indices and Metadata Archive (GSIM) - Part 1: The production of a daily streamflow archive and metadata. Earth System and Science Data, 10: 765-785.

FEPAM. Fundação Estadual de Proteção Ambiental Henrique Luiz Roessler. 2018. Região hidrográfica do Guaíba Disponível em: http://www.fepam.rs.gov.br/qualidade/ guaiba.asp. Acesso em: 23 junho 2018.

Gartner, J.W. 2004. Estimating suspended solids concentrations from backscatter intensity measured by acoustic Doppler current profiler in San Francisco Bay, California. Marine Geology, 211: 169-187.

Guerrero, M., Szupiany, R.N. \& Amsler, M. 2011. Comparison of acoustic backscattering techniques for suspended sediments investigation. Flow Measurement and Instrumentation, 22: 392-401.

Heininger, P., Höss, S., Claus, E., Pelzer, J. \& Traunspurger, W. 2007. Nematode communities in contaminated river sediments. Environmental Pollution, 146: 64-76.

Heise, S. \& Forstner, U. 2007. Risk assessment of contaminated sediments in river basinstheoretical considerations and pragmatic approach. Journal of Environmental Monitoring, 9: 943-952.

JORNAL DO COMÉRCIO. Catamarã beneficia trabalhadores e promove o turismo Jornal do Comércio. Disponível em: http:// www.jornaldocomercio.com/_conteudo/ geral/2018/06/631043-catamara-eneficia- trabalhadores-e-promove-o-turismo.html. Acesso em: 23 junho de 2018.

Laybauer, L. \& Bidone, E. 2001 Caracterização Textural dos Sedimentos de Fundo do Lago Guaíba (sul do Brasil) e sua Importância em Diagnósticos Ambientais. Pesquisas em Geociências, 28(1): 13-17126.

Liu, C., Walling, D.E., Spreafico, M., Ramasamy, J., Thulstrup, H.D. \& Mishra, A. 2017. Sediment Problems and Strategies for their Management Experience from several large river basins. United Nations Educational, Scientific and Cultural Organization, 16p.

Livi, P. 1998. Elementos do clima: o contraste dos tempos frios e quentes. In: Menegat, R., Porto, M.L., Carraro, C.C., Fernandes, L.A.D, (Ed.) Atlas Ambiental de Porto Alegre, Porto Alegre, Ed. Universidade / UFRGS. p. 73-78.

Menegat, R. \& Carraro, C.C. 2009. Manual para saber por que o Guaíba é um lago. Porto Alegre, Armazém Digital, 108p.

Möller, O.O., Castaing, P., Fernandes, E.H.L. \& Lazure, P. 2007. Tidal frequency dynamics of a southern Brazil coastal lagoon: choking and short period forced oscillations. Estuaries and Coasts, 30(2): 311-320.

Nicolodi, J.L. 2007. O padrão de ondas no Lago Guaíba e sua influência nos processos de sedimentação. Porto Alegre, 179p. Tese de Doutorado, Programa de Pós-graduação em Geociências, Instituto de Geociências, Universidade Federal do Rio Grande do Sul.

Nicolodi, J.L., Toldo, E.E. \& Farina, L. 2010. Dinâmica e ressuspensão por ondas no lago Guaíba e suas implicações nos locais de captação de água para abastecimento humano. Pesquisas em Geociências, 37(1): 25-39.

Nicolodi, J.L., Toldo Jr., E.E. \& Farina, L. 2013. Dynamic and resuspension by waves and sedimentation pattern definition in low energy environments. Guaíba Lake (Brazil). Brazilian Journal of Oceanography, 61: 55-64.

Nihei, Y. \& Kimizu, A. 2008. A new monitoring system for river discharge with horizontal acoustic Doppler current profiler measurements and river flow simulation. Water Resources Research, 44: 1-15.

Oeurng, C., Sauvage, S. \& Sánchez-Pérez, J.M. 
2010. Dynamics of suspended sediment transport and yield in a large agricultural catchment, southwest France. Earth Surface Processes and Landforms, 35(11): 1289-1301. Porcher, C.A., Lopes, R.C. 2000. Folha SH.22-Y-A Cachoeira do Sul, estado do Rio de Grande do Sul. Rio de Janeiro. Companhia de Pesquisa de Recursos Minerais (CPRM). Programa Levantamentos Geológicos Básicos do Brasil, escala 1:250.000.

Rovira, A. \& Batalla, R.J. 2006. Temporal distribution of suspended sediment transport in a Mediterranean basin: The Lower Tordera (NE SPAIN). Geomorphology, 79: 58-71.

Salla, M.R., Arquiola, J.P., Elvira, N.L., Alamy Filho, J.E., Pereira, C.E. \& Costa, E.S. 2015. Aplicação da ferramenta EVALHID para calibração de parâmetros e simulação de vazões no alto curso do rio Araguari, Minas Gerais. Revista Brasileira de Recursos Hídricos, 20(1): 276285.

Scottá, F.C., Andrade, M.M., Silva Junior, V.O., Oliveira, N., Weschenfelder, J., Bortolin, E. \& Nunes, J.C. 2019. Padrões geoacústicos do fundo e subfundo do rio Guaíba e suas relações como os processos sedimentares e hidrodinâmicos. Revista Brasileira de Geofísica, 37(1): 1-16.

Shepard, F. P. 1954. Nomenclature based on sand-silt-clay ratios. Journal of Sedimentary Petrology. 24:151-158.

SMAD. Sistema de Monitoramento e Alertas de Desastres. 2017. Cais Mauá C6. http://www.smad.rs.gov. br/estacoes/informacaoDaEstacao. php?codigo $=87450004$. Acesso em: 18 maio 2017.

Sontek. 1997. Using signal strength data to monitor suspended sediment concentration. San Diego, SonTek Inc., 7p.

Sontek. 2000. SONTEK ADP Acoustic Doppler Profiler technical documentation. San Diego, SonTek Inc., 186p.
Toldo Jr., E.E.; Dillenburg, S.R.; Corrêa, I.C.S. \& Almeida, L.E.S.B. 2000. Holocene Sedimentation in Lagoa dos Patos Lagoon, Rio Grande do Sul, Brazil. Journal of Coastal Research, 16(3):816-822.

Toldo Jr., E.E. \& Almeida, L.E.S. 2012. Rio Guaíba. Porto Alegre, Centro de Estudos de Geologia Costeira e Oceânica, 8p.

Toldo Jr., E.E. 1994. Sedimentação, Predição do Padrão de Ondas, e Dinâmica Sedimentar da Antepraia e Zona de Surfe do Sistema Lagunar da Lagoa dos Patos. Porto Alegre, 183 p. Tese de Doutorado, Programa de Pós-graduação em Geociências, Instituto de Geociências, Universidade Federal do Rio Grande do Sul.

Van Dorn, W.G. 1957. Large-volume water sampler. Trans. Am. Geophys. Union, 37: 682684.

Vaz, A.C., Möller Junior, O.O. \& Almeida, T.L. 2006. Análise quantitativa da descarga dos rios afluentes da Lagoa dos Patos. Atlântica, 28(1): 13-23.

Viana, D., Aquino, F.E. \& Matzenauer, R. 2006. Comportamento Espaço-Temporal da Precipitação no Rio Grande do Sul entre 1945-1974 e 1975-2004. In: CONGRESSO BRASILEIRO DE METEOROLOGIA, 14., Florianópolis. Anais...Florianópolis, p. 1 - 6.

Zaleski, A.R. \& Schettini, C.A.F. 2006. Procedimentos para calibração de perfiladores acústicos de corrente por Efeito Doppler para a determinação da concentração de material particulado em suspensão na água. Revista Brasileira de Recursos Hídricos, 11(3): 191200. 